\title{
Pharmacist interventions to enhance blood pressure control and adherence to antihypertensive therapy: Review and meta-analysis
}

\author{
Manuel P. Morgado, Sandra R. Morgado, Liliana C. Mendes, Luísa J. Pereira, \\ AND Miguel CASTElo-BranCO
}

$\mathrm{H}$ ypertension is a major risk factor for cardiovascular disease and an important public health problem worldwide. The risk of cardiovascular morbidity and mortality is particularly marked when there is insufficient hypertension control and prevention at the community level. Randomized controlled trials (RCTs) have demonstrated that treating high blood pressure (BP) with medication can substantially reduce the risk of stroke by $35-40 \%$ and myocardial infarction by $20-25 \% .^{1,2}$ Although the treatment of hypertension has been shown to reduce the risk of cardiovascular disease and mortality, hypertension remains inadequately managed worldwide, with a lack of adherence to BP-lowering medication playing a major role in poor BP control. ${ }^{3-7}$ Hypertensive patients may fail to take their medication because of the symptomless nature of the condition, the long duration of therapy, adverse effects of medi-
Purpose. Pharmacist interventions to enhance blood pressure (BP) control and adherence to antihypertensive therapy in adults with essential hypertension were reviewed.

Methods. A literature search was conducted to identify relevant articles describing pharmacist interventions intended to improve adherence to antihypertensive medications. Studies were included if they described a pharmacist intervention to improve medication adherence and analyzed adherence to therapy and BP control as outcomes. A fixed-effects model was used to combine data from randomized controlled trials.

Results. A total of 15 studies were identified, testing 16 different interventions and containing data on 3280 enrolled patients. Although $87.5 \%$ of the interventions resulted in significant improvements in treatment outcomes, only $43.8 \%$ of the interventions were associated with significant increases in medication adherence. All interventions that increased antihypertensive medication adherence also significantly reduced BP. Almost all the interventions that were effective in increasing adherence to medication were complex, including combinations of different strategies. Metaanalysis of 2619 patients in 8 studies found that pharmacist interventions significantly reduced systolic blood pressure (SBP) $(p<$ $0.001)$ and diastolic blood pressure (DBP) $(p=0.002)$ and that the meta-analytic differences in SBP and DBP changes from baseline to endpoint in intervention and control groups were $-4.9 \pm 0.9 \mathrm{~mm} \mathrm{Hg}$ $(p<0.001)$ and $-2.6 \pm 0.9 \mathrm{~mm} \mathrm{Hg}(p<0.001)$, respectively.

Conclusion. A literature review and metaanalysis showed that pharmacist interventions can significantly improve medication adherence, SBP, DBP, and BP control in patients with essential hypertension. Interventions were complex and multifaceted and included medication management in all analyzed studies.

Index terms: Blood pressure; Compliance; Hypertension; Hypotensive agents; Interventions; Patients; Pharmacists

Am J Health-Syst Pharm. 2011; 68:24153
Manuel P. Morgado, M.Sc., Pharm.D., is Pharmacist, Health Sciences Research Centre, University of Beira Interior (UBI), Covilhã, Portugal, and Senior Hospital Pharmacist, Hospital Centre of Cova da Beira (HCCB), Covilhã. SANDRA R. MORGADO, M.Sc., PHARM.D., is Senior Hospital Pharmacist, HCCB. LILIANA C. MENDES, M.SC., PHARM.D., is a Ph.D. student, Health Sciences Research Centre, UBI. Luísa J. Pereira, Ph.D., is Mathematician and Statistician, Mathematics Department, UBI. Miguel CASTElo-BRANCO, Ph.D., M.D., is Researcher, Health Sciences Research Centre, UBI, and Chief, Internal Medicine, HCCB.

Address correspondence to Dr. Morgado at the Health Sciences
Research Centre, University of Beira Interior, Avenue Infante D. Henrique, Covilhã 6200-506, Portugal (manuelaugustomorgado@ gmail.com).

Supported by fellowship grant SFRH/BD/36756/2007 from the Fundação para a Ciência e a Tecnologia.

The authors have declared no potential conflicts of interest.

Copyright () 2011, American Society of Health-System Pharmacists, Inc. All rights reserved. 1079-2082/11/0201-0241\$06.00.

DOI 10.2146/ajhp090656 
cation, complicated drug regimens, the lack of understanding about hypertension management, costs of medication, and the challenge to individual patients' health beliefs. ${ }^{8,9}$ Adherence rates to antihypertensive agents differ depending on the population studied, ranging between 50\% and $70 \% .5,10,11$

The importance of improving adherence to antihypertensive medication has been addressed by the seventh report of the Joint National Committee on Prevention, Detection, Evaluation, and Treatment of High Blood Pressure, emphasizing the role of all health care professionals, including pharmacists, to improve adherence to treatment. ${ }^{1}$ In the past two decades, pharmacists have been developing and implementing validated methods and services to improve adherence to antihypertensive medication and the clinical outcomes of this "silent" disease. ${ }^{12}$

One systematic review, which included studies from 1978 to 2006, assessed pharmacist interventions in hypertensive patients in order to enhance patients' adherence to medication and reduce systolic BP (SBP) and diastolic BP (DBP). ${ }^{13}$ Since then, several important RCTs ${ }^{14-17}$ and non-RCTs ${ }^{18-20}$ have been conducted to assess the effect of pharmacist interventions on medication adherence and BP control in hypertensive patients.

While there is strong evidence supporting the benefits of antihypertensive drug therapy, ${ }^{21}$ there is little clear evidence as to which types of pharmacist interventions for hypertensive patients are most effective for increasing medication adherence and improving hypertension control. We conducted a systematic review of published data on pharmacist interventions targeting antihypertensive medication adherence in adults with essential hypertension to evaluate the effect of pharmacist interventions on antihypertensive medication adherence and quantify the reductions in
SBP and DBP resulting from those interventions.

\section{Methods}

A literature search to identify pharmacist interventions intended to improve adherence to antihypertensive medications and BP control was conducted. To be included in the systematic review, studies had to (1) have a population of adults with essential hypertension currently treated with BP-lowering drugs in a primary care, an outpatient, or a community setting, (2) clearly describe and evaluate an intervention delivered by a pharmacist to improve adherence with antihypertensive drugs and BP control, and (3) include both adherence to antihypertensive medication and mean SBP, mean DBP, or BP control as outcomes. Studies describing multidisciplinary interventions were included only if the pharmacist's role in patient care was clearly described. Articles describing different health conditions (e.g., cardiovascular diseases not involving essential hypertension) were excluded, as were studies assessing SBP and DBP or BP control but not antihypertensive medication adherence. The criteria used to assess adherence and treatment outcome were based on the observation that studies showing an increase in adherence without an improvement in clinical outcome provide no practical guidance for practice. Articles were also required to be written in English, French, Spanish, German, Portuguese, or Italian.

We searched the main electronic databases freely available in our research center: MEDLINE, The Cochrane Library, and ISI Web of Knowledge. Each database was independently searched by two reviewers for articles published from January 1999 through June 2009, using the terms high blood pressure, hypertension, pharmaceutical services or pharmaceutical care or pharmacist, and patient outcomes (i.e., adherence, compliance, systolic blood pressure, di- astolic blood pressure, and blood pressure control). We also hand searched bibliographies of all retrieved articles to identify additional publications of pharmacist interventions on patient medication adherence.

Two authors independently selected articles by first reading titles, then abstracts, and, finally, full texts. The reviewers selected articles based on the predefined inclusion and exclusion criteria and then compared results. Any disagreements were resolved by consensus. The rationale for decisions was discussed until reviewers agreed on the final decision. A third author was called to resolve any remaining discrepancies concerning article eligibility.

Data extraction was also performed by two independent authors, and disagreements were resolved through the same consensus process used with article selection. The following data were obtained in duplicate and verified: year of publication, study design, use of a comparison group, type of pharmacist interventions, extent of follow-up, study setting, sample size of both intervention and control groups, patients lost to follow-up, methods used to measure medication adherence, and outcomes measured. The outcomes of particular interest were medication adherence, SBP, DBP, and BP control. During data extraction, we wrote to corresponding authors of studies to request missing data and clarify study details.

After data were extracted, we classified study outcomes as either sensitive or nonsensitive. Sensitive results were those that were influenced positively by the pharmacist intervention from a clinical point of view and that had statistical significance (i.e., $p$ of $\leq 0.05$ at the endpoint of the study). Pharmacist interventions aimed to increase adherence to BP-lowering medication and BP control were classified as (1) medication management (drug therapy monitoring and adjustments; simplification of anti- 
hypertensive regimens; optimization of drug regimen in order to solve adverse drug reactions, drug-drug interactions, and food-drug interactions; generic substitution), (2) educational interventions directed at the patient (hypertension education, BP self-monitoring recommendation, lifestyle education and counseling, medication education and counseling), (3) self-monitoring and recording of $\mathrm{BP}$, including education, encouragement, and validatation of BP monitor, (4) medication reminders, including education and counseling tips (adherence aids), and appointment reminders (e.g., telephone or computer-based), (5) improved administration systems (e.g., Medication Event Monitoring System [Aardex Group Ltd., Slon, Valais, Switzerland]), and medications dispensed using an adherence aid (e.g., blister packs), (6) morefrequent follow-up appointments or contacts, (7) educational interventions and alerts directed at the health care professional (personal, telephone- or computer-based), and (8) pharmacist clinical visits in medical, university, hospital, and community-based clinics.

Two reviewers assessed the quality of accepted studies independently and in duplicate, using the quality scale of Downs and Black, ${ }^{22}$ which was developed based on epidemiologic principles, reviews of study designs, and existing checklists for assessing RCTs. Disagreements regarding study quality were handled by consensus, and additional information about study design was requested from the authors if necessary. The method of Downs and Black $^{22}$ has been validated, and it allows for the scoring of quality of RCTs and observational studies. The instrument consists of a 28 -item checklist that addresses a study's quality of reporting (10 items), external validity ( 3 items), internal validity or bias (7 items), confounding variables (6 items), power (1 item), and a global score (1 item assessing the rater's overall impression of the quality of a paper) and has a possible total score of 42 (corresponding to the maximum quality score of $100 \%$ ). Scores below $50 \%$ were considered weak, those between 50\% and $69 \%$ were considered fair, scores of $70-79 \%$ were good, and scores of $80-100 \%$ were very good. We used a Mann-Whitney $U$ test to compare quality scores between sensitive and nonsensitive outcomes, because there may be a relationship between the methodological quality of the included studies and the success of their respective interventions.

Medication adherence was reported in the individual groups of the studies at baseline and end of study. Whenever feasible, the percentage of participants with controlled BP at the end of the study and the corresponding odds ratio were mentioned. In each study, BP was classified as controlled using the national or international guidelines applicable at the time of the study. Because of the substantial differences among selected studies in terms of the various methods that were used to measure adherence (e.g., prescription refill data, pill count, compliance questionnaire, plasma drug level), we believed that pooling of the medication adherence results was inappropriate. A fixed-effects meta-analytic model was used to combine SBP and DBP results. However, only studies with extractable data and that had a contemporary control group were included in the meta-analysis (i.e., subjects allocated to usual care [control group] were treated during the same time period [contemporary] as the intervention group) to ensure that the only difference between the groups was the pharmacist intervention under investigation.

We explored the potential for publication bias by using funnel plots and calculating the BeggMazumdar ${ }^{23}$ statistic. We examined the heterogeneity of outcomes us- ing the chi-square test. ${ }^{24}$ All analyses were conducted with SPSS, version 17.0 (SPSS Institute, Chicago, IL) and Comprehensive Meta-Analysis, version 2.0 (Biostat, Englewood, NJ), and the a priori level of significance was 0.05 .

\section{Results}

Initially, 225 potential articles were identified. After assessing their titles and excluding those not mentioning any information pertinent to hypertension, BP, or medication adherence studies, 130 remained and their abstracts read. Of the 47 articles retrieved for full-text review, 32 were excluded for the following reasons: not an interventional study, ${ }^{25-27}$ studied participants with a different disease not relevant to review, ${ }^{28-32} \mathrm{did}$ not include pharmacists in the study interventions, ${ }^{33}$ presented pharmaceutical interventions and outcomes investigating neither adherence nor $\mathrm{BP},{ }^{34-37}$ presented pharmaceutical interventions and outcomes investigating BP but not adherence, ${ }^{38-53}$ investigated medication adherence outcome in the intervention group only and baseline adherence was not measured, ${ }^{54}$ and not studies but reviews. ${ }^{13,55} \mathrm{~A}$ total of 15 articles were included as full-text in our systematic review. ${ }^{14-20,56-63}$

Table 1 details some characteristics of the included studies. One study tested different interventions in three distinct intervention groups. ${ }^{16}$ In this study the authors attributed the simplest intervention (provider education) to the control group and the remaining interventions ("provider education and alert" and "provider education and alert and patient education") to two intervention groups. Another study included two pharmacistintervention groups, designated as a high-intensity intervention and a low-intensity intervention. We considered the low-intensity group, in which the only pharmacist intervention was measurement of $\mathrm{BP}$ and 
Table 1.

Characteristics of Studies Evaluating Pharmacists' Interventions in Hypertension Treatment ${ }^{\mathrm{a}}$

\begin{tabular}{|c|c|c|c|c|}
\hline Ref. & Study Design ${ }^{b}$ & Setting (Country) & $\begin{array}{l}\text { Pharmacist } \\
\text { Intervention }\end{array}$ & $\begin{array}{c}\text { Frequency of } \\
\text { Pharmacist-Patient } \\
\text { Interaction in } \\
\text { Intervention Group }\end{array}$ \\
\hline 14 & $\mathrm{RCT}$ & $\begin{array}{l}\text { Community-based primary care clinics (United } \\
\text { States) }\end{array}$ & $A, B, C$ & Mean, 7.2 times in $12 \mathrm{mo}^{\mathrm{d}}$ \\
\hline 15 & $\mathrm{RCT}$ & Army medical center (United States) & $B, D$ & Every $2 \mathrm{mo}^{\mathrm{e}}$ \\
\hline 16 & Cluster RCT & $\begin{array}{l}\text { Hospital-based clinics (United States) } \\
\text { Community-based clinics (United States) }\end{array}$ & C & $>3$ times in $6 \mathrm{mo}^{f}$ \\
\hline 17 & Cluster RCT & University clinics (United States) & $A, B, C, E, F, G$ & $\begin{array}{l}\text { Mean } \pm \text { S.D., } 6.8 \pm 1.6 \text { times } \\
\quad \text { in } 9 \mathrm{mo}^{g}\end{array}$ \\
\hline 18 & SGCT & $\begin{array}{l}\text { Primary-care clinics and community } \\
\text { pharmacies (United States) }\end{array}$ & $A, B, C, E$ & 5 times in $9 \mathrm{mo}^{\mathrm{h}}$ \\
\hline 19 & SGCT & Clinic in university teaching hospital (Brazil) & $A, B, C, F$ & Mean, 10.5 times in $12 \mathrm{mo}^{\mathrm{h}}$ \\
\hline 20 & SGCT & Community pharmacy (Nigeria) & $A, B, C, E$ & Monthly ${ }^{h}$ \\
\hline 56 & $\mathrm{RCT}$ & Community pharmacies (United Kingdom) & $A, B$ & Every $2 \mathrm{mo}^{\mathrm{i}}$ \\
\hline 57 & SGCT & Aircraft carrier (United States) & A & Every $2 w^{h}$ \\
\hline 58 & Non-RCT & Community pharmacies (Canada) & $A, B, C, F$ & Mean, 5.8 times in $9 \mathrm{mo}^{\mathrm{j}}$ \\
\hline 59 & $\mathrm{RCT}$ & Medical clinic (Brazil) & A & Monthly \\
\hline 60 & $\mathrm{RCT}$ & Medical clinic (United States) & $A, B, C, E$ & Monthly \\
\hline 61 & $\mathrm{RCT}$ & Community pharmacies (Thailand) & $A, B$ & Monthly \\
\hline 62 & RCT & Medical clinic (United States) & $A, B$ & Monthly \\
\hline 63 & $\mathrm{RCT}$ & Community pharmacies (United States) & $A, B, C, E$ & 4 times in $3 \mathrm{mo}^{\mathrm{k}}$ \\
\hline
\end{tabular}

a Medication adherence and blood pressure were measured in all studies. Other measured outcomes included quality of life, self-measurement of blood pressure, alcohol moderation, exercise, salt restriction, smoking cessation, number of antihypertensive drugs, adverse drugs effects, hypertension-related knowledge, patient satisfaction, resource utilization, low-density-lipoprotein cholesterol concentration, and intensification of antihypertensive regimen.

${ }^{\mathrm{b}} \mathrm{RCT}=$ randomized clinical trial, SGCT = single-group clinical trial.

In all studies, pharmacists' interventions included medication management (e.g., drug therapy monitoring or adjustment, simplification of antihypertensive regimens, resolution of adverse drug reactions). $\mathrm{A}=$ educational interventions directed to the patient (e.g., hypertension education, lifestyle education and counseling), $\mathrm{B}=$ scheduling more-frequent follow-up appointments or contacts, $\mathrm{C}=$ educational interventions and alerts directed to health care professionals, $\mathrm{D}=$ providing improved administration systems (e.g., medication event monitoring system, blister packs), E = instituting self-monitoring and recording of blood pressure, including education, encouragement, and validating blood pressure monitor, $\mathrm{F}=$ providing medication reminders, including education and counseling tips (adherence aid tools) and appointment reminders (e.g., telephone based, computer based), $\mathrm{G}=$ pharmacist clinical visit attendance.

Interaction in the control group occurred a mean of 4.9 times in 12 months.

eInteraction in the control group occurred at baseline and at the midpoint and end of the study.

finteraction in the control group occurred with the same frequency as in the intervention group.

Interaction in the control group occurred a mean \pm S.D. of $5.5 \pm 1.3$ times in 9 months.

hPatients at baseline served as their own controls.

Interaction in the control group occurred at baseline and at the end of the study.

Interaction in the control group occurred 4 times in 9 months.

kInteraction in the control group occurred 3 times in 3 months.

patient counseling to contact their physician whenever BP was above normal, as the control group.

Medication management, educational interventions directed to the patient, and more-frequent followup appointments or contacts were the most frequently used pharmacist interventions. The number of pharmacist interventions per study ranged from two to five. After BP values and medication adherence outcomes, which were evaluated in all tudies, patient quality of life was the most evaluated outcome, present in 6 of the 15 included studies. . $^{14,18-20,60,62}$

Table 1 also details the pharmacistpatient interaction in control and intervention groups of included studies. The most common frequency of pharmacist-patient interaction in the intervention group was between monthly and every two months, and the purpose of the interaction was to provide pharmacist interventions. The pharmacistpatient interaction in the control group involved mostly baseline, intermediate, and endpoint assessment of described outcomes.

Article quality scores, sample size, duration of follow-up, losses to follow-up, and outcomes sensitive to pharmacist interventions are shown in Table 2. The mean \pm S.D. article quality score was $67.5 \% \pm 10.6 \%$ (range, 50-76\%), which was considered fair. The mean \pm S.D. sample size was $218.7 \pm 331.7$ patients (median, 111 patients; range, 26-1341 patients). The follow-up period of the studies evaluated ranged from 
two weeks to 12 months, with an average duration of $6.7 \pm 10.6$ months. Losses to follow-up ranged from $3.4 \%$ to $48.5 \%$ (mean \pm S.D., $18.9 \%$ $\pm 15.3 \%)$. Article quality scores did not increase from 2000 to $2008(y$ $=596.848-0.264 x, r^{2}=0.006, p=$ 0.790 , where $y=$ article quality score and $x=$ publication year). Sixty-one percent of the outcomes $(28 / 46)$ were categorized as sensitive to the pharmacist interventions.

Effect on medication adherence and $\mathrm{BP}$ control. Adherence was measured in different ways, including self-report (through questionnaire or direct questioning), pill counts, analysis of prescription refill data, and plasma levels of hydrochlorothiazide. Various criteria for adherence were used in the studies, making a pooled analysis inappropriate (Table $3)$. Baseline medication adherence to antihypertensive drugs ranged from $35 \%$ to $88.6 \%$, and medication adherence at study end ranged from $50 \%$ to $95.8 \%$, which points to an increase in medication adherence due to pharmacist interventions. In fact, 7 of 16 intervention groups demonstrated a significant improvement in medication adherence when compared with the control groups. Differences in adherence rates at study end between pharmacist intervention groups and control groups varied from $8 \%$ to $58 \%$ in studies with positive sensitive outcomes. Although 5 studies revealed that pharmacist interventions had a negative effect on patients' treatment adherence compared with the control group, which ranged from $-1 \%$ to $-8 \%$, these negative results were not significant. One study found an abnormally high increase in treatment adherence rate (increase of 58\% from baseline); however, no comparison group was used in this study, and the follow-up period was only two weeks. The correlation between article quality scores and impact of pharmacist interventions was $-0.680(p=0.004)$ for medication adherence. This ob-

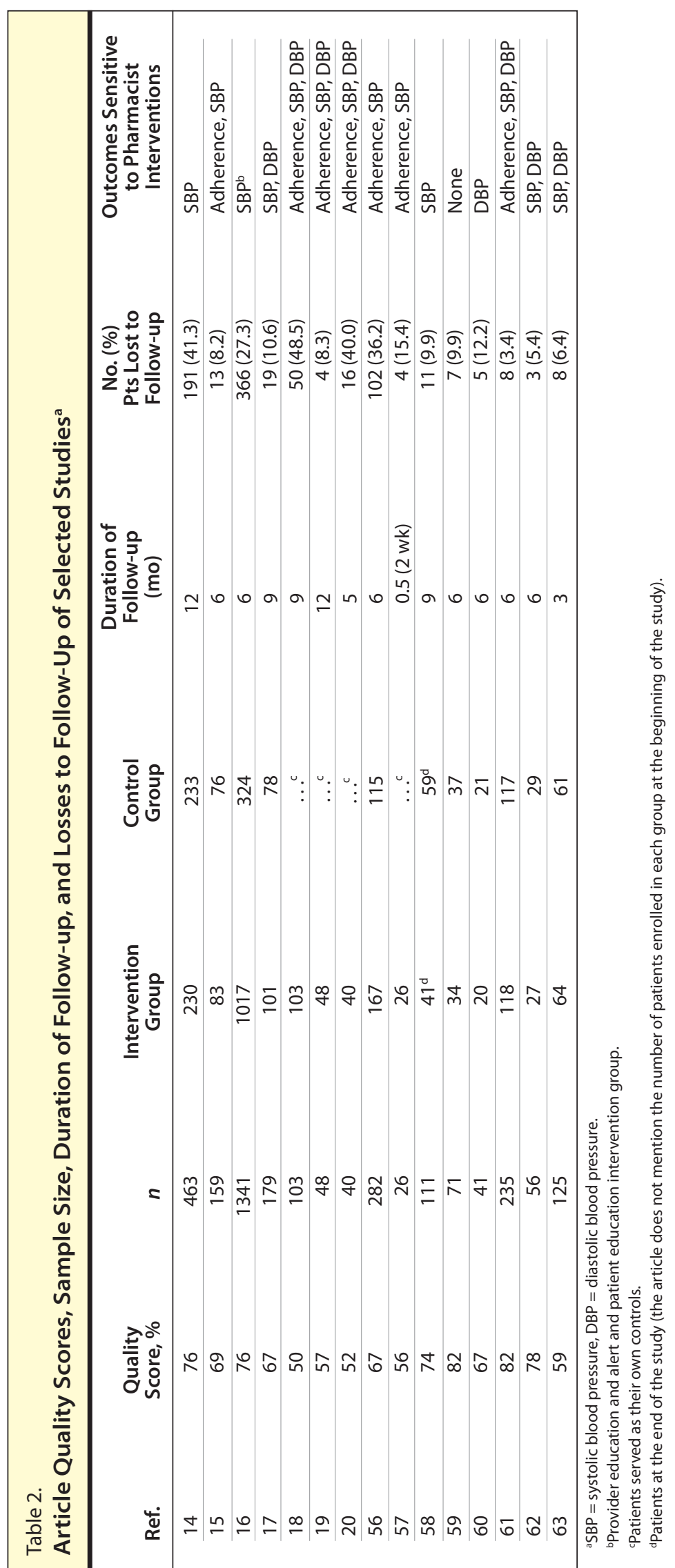




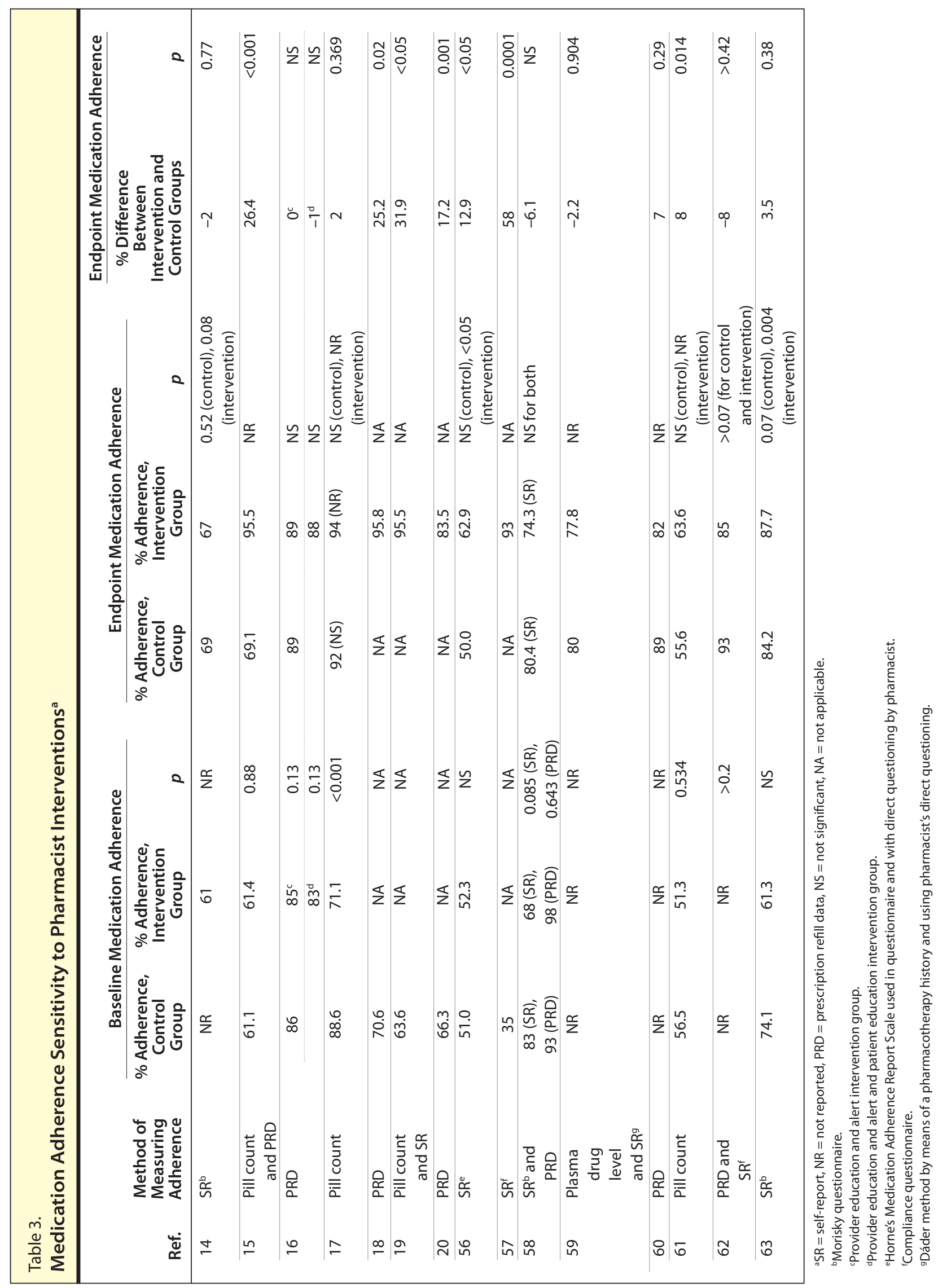


servation suggests that higher quality scores are associated with a lesser effect on medication adherence. All of the 4 single-group controlled trials evaluated (with no contemporary comparison control group) reported a significant increase in medication adherence. The remaining 3 studies, which were RCTs, that reported a significant increase in medication adherence had more-frequent follow-up with the intervention group. Six other studies also adopted more-frequent follow-up without a significant increase in medication adherence. In 5 of these 6 studies, the endpoint adherence rate was high $(>80 \%)$ in the control group, possibly making it difficult to achieve a further increase in the intervention group. Indeed, all 7 studies with a high adherence rate at study endpoint $(>80 \%)$ in the control group found that pharmacist interventions had a nonsignificant effect on medication adherence. All other studies but 1 revealed that pharmacist interventions had a positive effect on medication adherence, with a mean difference in adherence rates at endpoint between intervention and control groups of $22.2 \%$.

Likewise, various criteria were used to report BP outcome, making it inappropriate to pool data from all included studies, though the range of results from individual studies are presented (Table 4). Of the 15 studies evaluated, 2 did not measure SBP or DBP, 7 studies described a significant improvement in both SBP and DBP, 4 described a significant improvement in SBP alone, and 1 study noted a significant improvement in DBP alone. Significant improvements in SBP and DBP ranged from -5.0 to
$-18.6 \mathrm{~mm} \mathrm{Hg}$ and from -1.0 to -12.2 $\mathrm{mm} \mathrm{Hg}$, respectively.

Three of the included studies did not describe the percentage of participants with controlled BP at the end of the study. Seven studies found a significant increase in the percentage of participants with controlled BP at the end of the study when comparing intervention and control groups, which ranged from $17.5 \%$ to $51.0 \%$. The authors of each study classified BP as controlled using the national or international guidelines applicable at the time of the study (in most studies, BP was considered controlled when SBP was $<140 \mathrm{~mm}$ $\mathrm{Hg}$ and DBP was $<90 \mathrm{~mm} \mathrm{Hg}$ ). In 11 studies, we were able to calculate the odds ratio for the rate of patients achieving controlled $\mathrm{BP}$ at endpoint in the intervention group compared with the control group, and a range

Table 4.

Effects of Pharmacist Interventions on Blood Pressure (BP) Control ${ }^{\text {a }}$

\begin{tabular}{|c|c|c|c|c|c|c|}
\hline \multirow[b]{3}{*}{ Ref. } & \multirow{2}{*}{\multicolumn{2}{|c|}{$\begin{array}{l}\text { Difference in BP in Intervention } \\
\text { vs. Control Group, } \mathrm{mm} \mathrm{Hg}(p)\end{array}$}} & \multicolumn{2}{|c|}{$\begin{array}{l}\% \text { Pts With Controlled BP at } \\
\text { End of Study }\end{array}$} & \multirow[b]{3}{*}{$p$} & \multirow[b]{3}{*}{ OR (95\% Cl) } \\
\hline & & & \multirow{2}{*}{$\begin{array}{l}\text { Control } \\
\text { Group }\end{array}$} & \multirow{2}{*}{$\begin{array}{l}\text { Intervention } \\
\text { Group }\end{array}$} & & \\
\hline & SBP & DBP & & & & \\
\hline 14 & $5.0(<0.001)$ & $1.0(0.235)$ & 44.0 & 62.0 & 0.003 & $2.1(1.4-3.0)$ \\
\hline 15 & $7.3(0.001)$ & $1.4(0.216)$ & NR & NR & NR & NR \\
\hline \multirow[t]{2}{*}{16} & $-0.3(\mathrm{NS})^{\mathrm{b}}$ & $1.3(\mathrm{NS})^{\mathrm{b}}$ & 42.0 & 59.5 & 0.003 & $2.0(1.5-2.7)$ \\
\hline & $6.0(<0.001)^{c}$ & $3.3(\mathrm{NS})^{\mathrm{c}}$ & & & & \\
\hline 17 & $11.6(<0.001)$ & $3.3(0.005)$ & 52.9 & 89.1 & $<0.001$ & $7.2(3.2-15.6)$ \\
\hline 18 & $16.7(0.02)$ & $12.2(0.04)$ & NR & NR & NR & NR \\
\hline 19 & $18.6(<0.05)$ & $9.1(<0.05)$ & 0 & 41.0 & $<0.05$ & $12.2(4.6-32.5)$ \\
\hline 20 & $14.3(<0.001)$ & $10.8(<0.001)$ & NR & NR & NR & NR \\
\hline 56 & NR & NR & 17.1 & 35.7 & $<0.05$ & $2.7(1.5-4.7)$ \\
\hline 57 & NR & NR & 42.0 & 73.0 & 0.02 & $3.7(1.2-11.9)$ \\
\hline \multirow[t]{2}{*}{58} & HI: 8.3 (0.01) & HI: 2.5 (0.28) & HI: 42.0 & HI: 69.0 & 0.073 & $3.1(0.8-12.4)$ \\
\hline & LI: -4.4 (NS) & LI: -2.5 (NS) & LI: NS & LI: NS & 0.895 & NS \\
\hline 59 & $5.0(0.063)$ & $2.0(0.281)$ & NS & NS & NS & NS \\
\hline 60 & $10.1(0.069)$ & $6.7(0.022)$ & 22.0 & 44.0 & $>0.1$ & $2.8(0.7-10.8)$ \\
\hline 61 & $5.7(0.001)$ & $2.5(0.029)$ & 57.2 & 66.1 & 0.061 & $1.5(0.9-2.5)$ \\
\hline \multirow[t]{2}{*}{62} & $14.1(<0.001)$ & $14.8(<0.001)$ & 30.0 & 81 & $<0.001$ & $9.8(2.8-34.1)$ \\
\hline & & & $\begin{array}{c}12.0 \\
\text { (diabetic pts) }\end{array}$ & $\begin{array}{c}91.0 \\
\text { (diabetic pts) }\end{array}$ & $<0.001$ & $70.0(5.6-882.2)$ \\
\hline 63 & $4.6(0.041)$ & $3.2(0.014)$ & 30.0 & 42.0 & 0.45 & $1.7(0.8-3.5)$ \\
\hline
\end{tabular}

aSBP = systolic blood pressure, $\mathrm{DBP}=$ diastolic blood pressure, $\mathrm{OR}=$ odds ratio, $\mathrm{Cl}=$ confidence interval, $\mathrm{NR}=$ not reported, $\mathrm{HI}=$ high income, $\mathrm{LI}=$ low income, NS = not significant.

bProvider education and alert intervention group.

cProvider education and alert and patient education intervention group. 
of 1.46-12.18 was obtained, with a mean \pm S.D. value of $4.43 \pm 3$.6.

Of the 7 studies that found a significant improvement in both SBP and DBP, $42.9 \%$ were single-group controlled trials (with no contemporary comparison control group). Thus, we analyzed the correlation between article quality scores and the impact of pharmacist interventions on SBP and DBP. This correlation was $-0.599(p=0.018)$ for SBP and -0.659 ( $p=0.007)$ for DBP. These observations suggest that higher quality studies are associated with a lesser effect on BP control.

A total of 8 controlled trials were included in the meta-analysis (Table 5). The remaining 7 studies were not included because the data were not extractable $e^{5,58,60}$ and a comparison contemporary control group was not used. ${ }^{18-20,57}$

Effects on SBP. Sensitive outcomes were reported in 11 of 13 studies evaluating SBP. It was possible to include only 8 studies for the meta-analysis of SBP outcomes. A funnel plot (data not shown) did not rule out the possibility of publication bias; therefore, we applied the trimand-fill method, ${ }^{64}$ which increased the difference in SBP change between intervention and placebo from 4.9 to $5.6 \mathrm{~mm} \mathrm{Hg}(p<0.001)$. However, the Begg-Mazumdar ${ }^{23}$ statistic was very small and nonsignificant $(t<0.001$, $p=1.0)$. The $Q$ statistic for heterogeneity of effects was not significant $\left(\chi^{2}=0.741, p=0.99\right)$; therefore, we considered the study results to be combinable.

The meta-analytic mean \pm S.D. baseline and endpoint SBPs in the pharmacist intervention group were $153.0 \pm 4.7$ and $130.9 \pm 4.6 \mathrm{~mm} \mathrm{Hg}$, respectively, producing a clinical and statistical weighted difference of $-19.4 \pm 3.5 \mathrm{~mm} \mathrm{Hg}(p<0.001)$. A significant difference was also observed in the mean \pm S.D. SBP from baseline $(151.3 \pm 4.9 \mathrm{~mm} \mathrm{Hg})$ to endpoint $(137.5 \pm 6.4 \mathrm{~mm} \mathrm{Hg})$ in the control group, with a meta-analytic difference of $-11.3 \pm 4.2(p=0.007)$. Meta-analytic differences from baseline to endpoint of both groups were calculated and are presented in Figure 1 . The meta-analytic mean \pm S.D. difference in SBP from baseline to endpoint between intervention and control groups was $-4.9 \pm 0.9 \mathrm{~mm} \mathrm{Hg}$ $(p<0.001)$.

Effects on DBP. Sensitive outcomes were reported in 8 of 13 studies evaluating DBP. It was possible to include only 7 studies for the meta-analysis of DBP evaluation. The funnel plot was similar to that for SBP (data not shown). Use of the trim-and-fill method increased the difference between intervention and placebo from 2.6 to $3.3 \mathrm{~mm} \mathrm{Hg}(p<0.001)$. However, the Begg-Mazumdar ${ }^{23}$ statistic did not detect publication bias $(\tau=-0.09, p=0.76)$. The $Q$ statistic found no heterogeneity of effects $\left(\chi^{2}=2.23, p=0.90\right)$, so the results were considered combinable.

The meta-analytic mean \pm S.D. baseline and endpoint DBPs in the pharmacist intervention group were $82.6 \pm 4.3$ and $74.6 \pm 3.8 \mathrm{~mm} \mathrm{Hg}$, respectively, producing a clinical and statistical weighted difference of -8.8 $\pm 2.9 \mathrm{~mm} \mathrm{Hg}(p=0.002)$. However, a nonsignificant difference was observed in DBP from baseline (81.7 \pm $4.3 \mathrm{~mm} \mathrm{Hg})$ to endpoint $(76.9 \pm 4.2$ $\mathrm{mm} \mathrm{Hg}$ ) in the control group, with a meta-analytic difference of $-4.9 \pm 3.0$ $\mathrm{mm} \mathrm{Hg}(p=0.103)$. Meta-analytic differences from baseline to endpoint of both groups were calculated and are presented in Figure 1. Pharmacist intervention reduced the DBP of the intervention group an additional 2.6 $\pm 0.9 \mathrm{~mm} \mathrm{Hg}$ when compared with the control group $(p<0.001)$.

\section{Discussion}

The majority of the studies included in our analysis were RCTs. Although the mean quality of these RCTs was considered good (quality score, $72.3 \%$ ), the mean quality of all the studies evaluated was fair (quality score, 67.5\%). It is not fea- sible to blind hypertensive patients in pharmaceutical intervention models, as this process of blinding is assessed in one item of the Downs and Black ${ }^{22}$ quality checklist. By removing this item, the average quality of all articles included would increase to over $70 \%$. However, 6 studies in which patients were not randomized to intervention groups, which are assessed by two items of the Downs and Black quality checklist, prevented a further increase of the overall quality score.

Although $88 \%$ of the interventions tested (14 of 16 in 15 studies) resulted in significant improvements in treatment outcomes (SBP, DBP, or percentage of participants with controlled BP at the end of the study), only $44 \%$ of the interventions (7 of 16 in 15 studies) were associated with significant increases in medication adherence. These results were higher than those obtained by Machado et al., ${ }^{13}$ who found that $76.6 \%$ and $38.5 \%$ of studies analyzed reported improvement in treatment outcomes and in medication adherence, respectively, though they did not address BP control specifically. Differences obtained in the systematic review of Machado et al. $^{13}$ and in our review reflect a trend toward improved medication adherence and treatment outcomes obtained with the most recent studies, which included more interventions involving physician-pharmacist collaboration. ${ }^{14,16-20}$ In both systematic reviews, all studies that found a significant increase in medication adherence also demonstrated a significant improvement in treatment outcomes, revealing that medication adherence is a key factor (though not the only one) for achieving BP control.

Drug therapy adjustments may have contributed to improvements in BP control in studies where medication adherence rates did not significantly change. Some studies suggested that antihypertensive medications are frequently not intensified when $\mathrm{BP}$ remains uncontrolled (clinical in- 

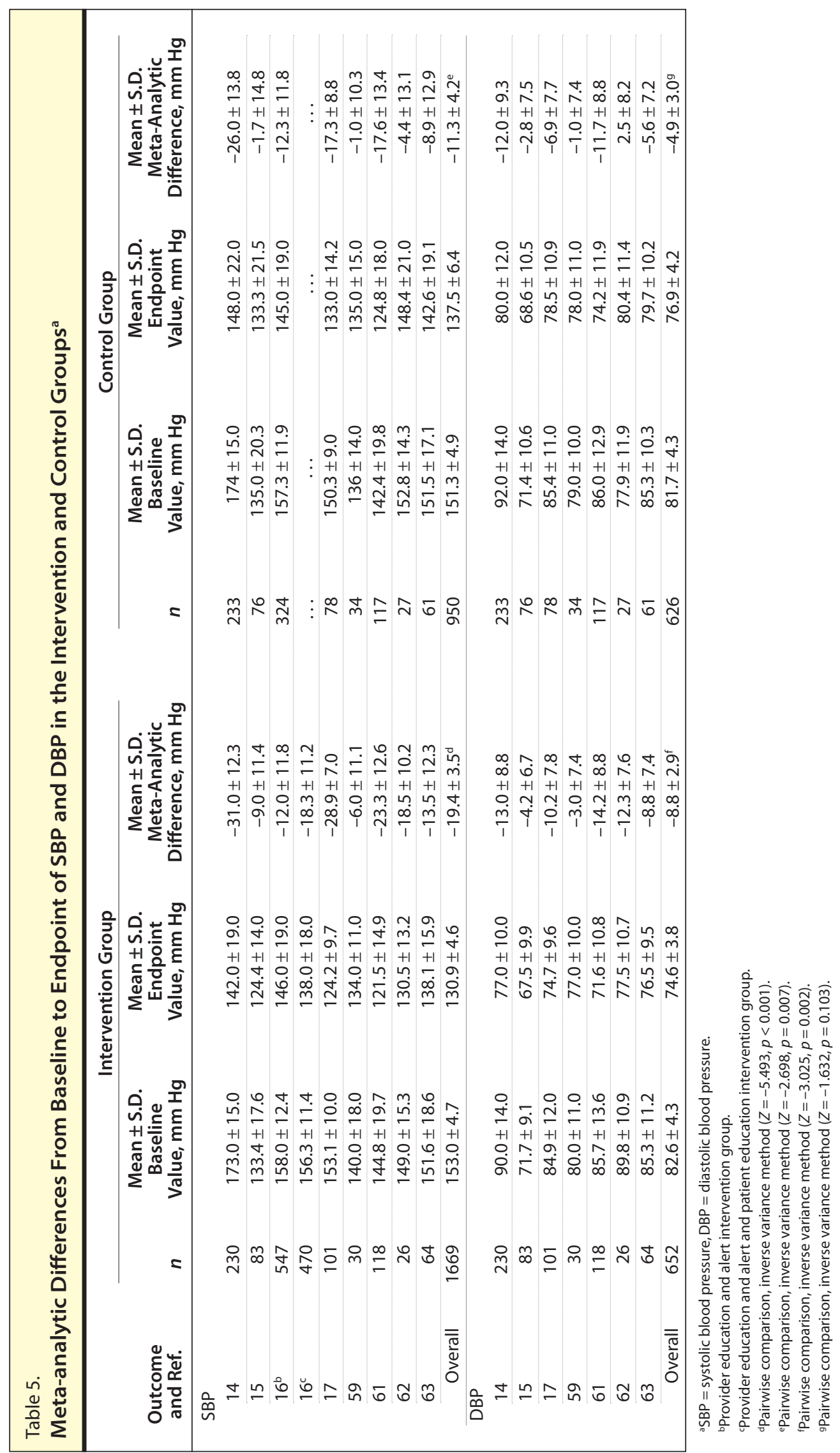
Figure 1. Meta-analytic differences in improvement of systolic blood pressure (SBP) and diastolic blood pressure (DBP) $(\mathrm{mm} \mathrm{Hg})$ between patients receiving a pharmacist intervention and patients in control groups. Negative estimates favor the intervention group over the control group in the reduction of SBP or DBP in hypertensive patients. The squares represent the difference in improvement between groups, with $95 \%$ confidence interval $(\mathrm{Cl})$.
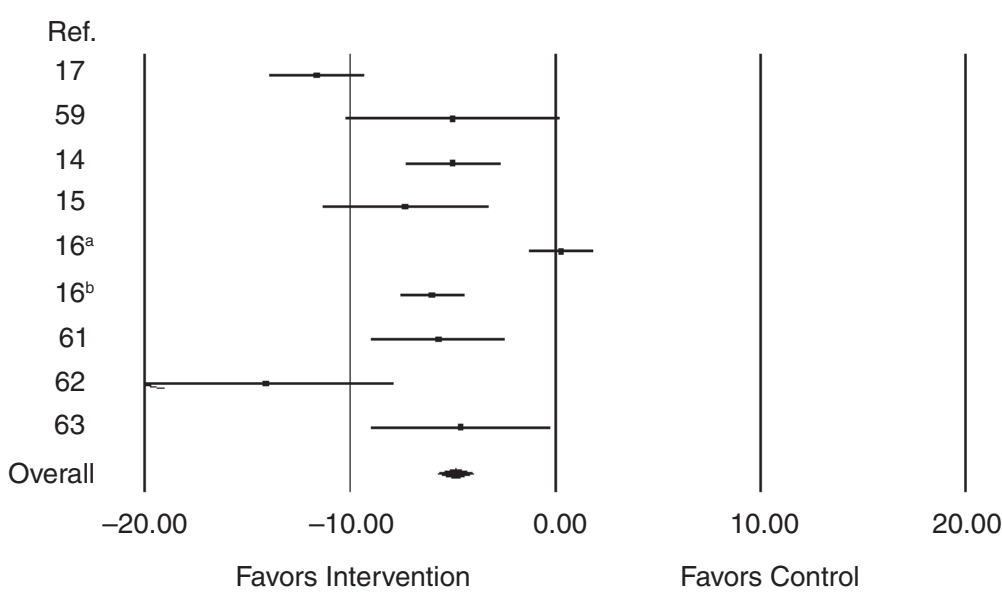

Difference in Means and $95 \%$ Cls for SBP

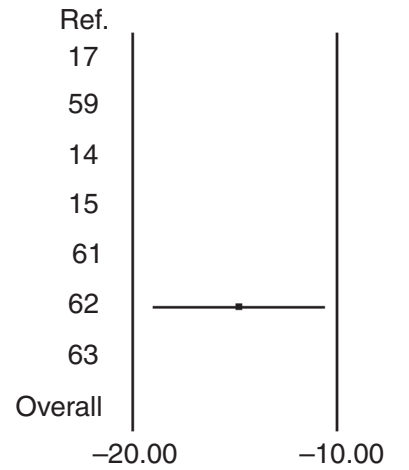

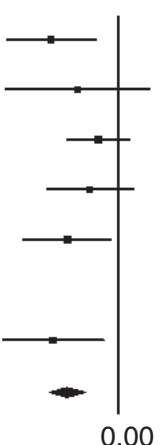

Favors Intervention

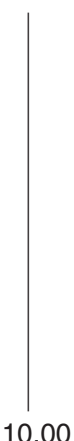

Favors Control

Difference in Means and $95 \%$ Cls for DBP

aProvider education and alert intervention group.

bProvider education and alert and patient education intervention group.

ertia). ${ }^{65,66}$ By addressing suboptimal medication regimens, pharmacists may have contributed to changing unsuccessful regimens, searching for those regimens that would be more likely to succeed. However, it is also possible that the several methods used to measure adherence, some of which were unreliable, may have contributed to the inconsistency in adherence-rate differences between control and intervention groups. Large high-quality trials that use reliable methods of measuring adherence are needed to investigate the relationship between adherence and $\mathrm{BP}$ reduction.

SBP and DBP were definitely sensitive to pharmacist interventions, as we found that baseline to endpoint reductions in these outcomes were significantly influenced in intervention groups compared with control groups. These results also differ from those obtained by Machado et al., ${ }^{13}$ whose review showed that only SBP was sensitive to pharmacist interventions.

Almost all the interventions that were effective for medication adherence or BP control improvements were complex, including combinations of medication management, educational programs directed at the patient, scheduling of morefrequent follow-up appointments, medication reminders, counseling, self-monitoring of $\mathrm{BP}$, and other forms of additional supervision or attention. We were not able to find a pattern of types or numbers of interventions that predicted success. Methods for improving antihypertensive adherence and BP control were generally labor-intensive (and therefore expensive) and not predictably effective. However, many intervention programs did lead to improved adherence or treatment outcomes. In 10 studies, we were able to calculate the odds ratio for the rate of patients achieving targeted BP at endpoint in the intervention group when compared with the control group, and a range of $1.46-12.18$ was obtained, with a mean \pm S.D. value of $4.43 \pm 3.6$. These values imply that achieving controlled BP at the end of the study was more likely in the intervention group and are in accordance with the values obtained by Carter et al. ${ }^{67}$ In addition, studies with the largest effect sizes (i.e., the largest reductions in SBP or DBP from baseline to endpoint) had higher mean baseline SBP and DBP values (Table 5). Thus, the clinical impact of pharmacist interventions in hypertensive patients is expected to be more pronounced in high-risk patients. Moreover, it is possible that some pharmacist intervention programs put more emphasis on better communication and empathetic reinforcement, as these actions build trust, are potent motivators, and tend 
to improve outcomes. ${ }^{1}$ Motivation improves when patients have positive experiences with and trust in their health care staff. More studies are needed to assess the role of communication and empathetic reinforcement skills of pharmacists and other health care personnel on patient motivation and outcomes improvement.

Our study had several limitations. Comparing the different studies included in this review was difficult due to marked heterogeneity in terms of research designs, interventions, duration of follow-up, methods to measure medication adherence, and reporting of clinical outcomes. Some studies demonstrated poor methodological quality, particularly with regard to the presence of a contemporary comparison control group, randomization, blinding of outcomes assessment, and losses to follow-up. In two studies, the duration of follow-up was too short (three months or less), which is considered inadequate to classify adherence rates accurately ${ }^{25,68}$ and to demonstrate persistent positive clinical findings. ${ }^{69}$

Adherence was measured and calculated in various ways, which made a pooled analysis inappropriate. For example, in one study, ${ }^{58}$ the baseline adherence measured by the Morisky et al. ${ }^{70}$ questionnaire was $83 \%$ and $68 \%$ in the control and intervention groups, respectively. When using refill-data analysis, the baseline adherence of the same patients was $93 \%$ and $98 \%$ in the control and intervention groups, respectively. Medication adherence was usually assessed unblinded to allocation status, which constitutes a potential source of bias. Without an agreement on criteria to measure and define medication adherence, it is not surprising that the effect of most interventions on adherence and BP was variable, making it difficult to examine the relationship between medication adherence and subsequent BP control.

We were not able to include several studies in our meta-analysis of
SBP and DBP in the intervention and control groups, because some studies either did not report these data or did not use a comparison or control group. One other limitation is based on the quality of pharmacist interventions made. It is possible that the same pharmacist intervention led to different results, depending on the empathetic reinforcement and motivation provided by the health care personnel that have contact with hypertensive patients. Therefore, some degree of variation of results is expected in clinical pharmacy practice. Another limitation is our literature search was conducted using the main electronic databases freely available in our research center, leaving out important databases like International Pharmaceutical Abstracts and EMBASE. We tried to circumvent this limitation by hand searching bibliographies of all retrieved articles to identify additional publications of pharmacist interventions on patient medication adherence. Finally, a chance of publication bias cannot be ruled out based on funnel plot analyses and the trim-and-fill method, though our search criteria were intended to capture all published articles evaluating pharmacist interventions on both antihypertensive medication adherence and BP control. Publication bias occurs when authors are more likely to submit, or editors accept, positive rather than null (negative or inconclusive) results. A search performed for unpublished data would have helped to minimize the occurrence of publication bias.

\section{Conclusion}

A literature review and metaanalysis showed that pharmacist interventions can significantly improve medication adherence, SBP, DBP, and $\mathrm{BP}$ control in patients with essential hypertension. Interventions were complex and multifaceted and included medication management in all analyzed studies.

\section{References}

1. Chobanian AV, Bakris GL, Black HR et al. Seventh report of the Joint National Committee on Prevention, Detection, Evaluation, and Treatment of High Blood Pressure. Hypertension. 2003; 42:1206-52.

2. Collins R, Peto R, MacMahon S et al. Blood pressure, stroke, and coronary heart disease. Part 2, short-term reductions in blood pressure: overview of randomised drug trials in their epidemiological context. Lancet. 1990; 335:82738.

3. Godley P, Pham H, Rohack J et al. Opportunities for improving the quality of hypertension care in a managed care setting. Am J Health-Syst Pharm. 2001; 58:1728-33.

4. Whitworth JA. 2003 World Health Organization (WHO)/International Society of Hypertension (ISH) statement on management of hypertension. J Hypertens. 2003; 21:1983-92.

5. Schroeder K, Fahey T, Ebrahim S. How can we improve adherence to blood pressure-lowering medication in ambulatory care? Systematic review of randomized controlled trials. Arch Intern Med. 2004; 164:722-32.

6. Krousel-Wood M, Thomas S, Muntner P et al. Medication adherence: a key factor in achieving blood pressure control and good clinical outcomes in hypertensive patients. Curr Opin Cardiol. 2004; 19:357-62.

7. Munger MA, Van Tassell BW, LaFleur J. Medication nonadherence: an unrecognized cardiovascular risk factor. MedGenMed. 2007; 9:58.

8. Dowell J, Jones A, Snadden D. Exploring medication use to seek concordance with 'non-adherent' patients: a qualitative study. Br J Gen Pract. 2002; 52:24-32.

9. Ebrahim S. Detection, adherence and control of hypertension for the prevention of stroke: a systematic review. Health Technol Assess. 1998; 2:i-iv,1-78.

10. Psaty BM, Koepsell TD, Yanez ND et al. Temporal patterns of antihypertensive medication use among older adults, 1989 through 1992. An effect of the major clinical trials on clinical practice? JAMA. 1995; 273:1436-8.

11. Caro JJ, Speckman JL, Salas M et al. Effect of initial drug choice on persistence with antihypertensive therapy: the importance of actual practice data. CMAJ. 1999; 160:41-6.

12. Hepler CD, Strand LM. Opportunities and responsibilities in pharmaceutical care. Am J Hosp Pharm. 1990; 47:533-43.

13. Machado M, Bajcar J, Guzzo GC et al. Sensitivity of patient outcomes to pharmacist interventions. Part II: systematic review and meta-analysis in hypertension management. Ann Pharmacother. 2007; 41:1770-81.

14. Hunt JS, Siemienczuk J, Pape G et al. A randomized controlled trial of team-based care: impact of physicianpharmacist collaboration on uncon- 
trolled hypertension. J Gen Intern Med. 2008; 23:1966-72.

15. Lee JK, Grace KA, Taylor AJ. Effect of a pharmacy care program on medication adherence and persistence, blood pressure, and low-density lipoprotein cholesterol: a randomized controlled trial. JAMA. 2006; 296:2563-71.

16. Roumie CL, Elasy TA, Greevy R et al. Improving blood pressure control through provider education, provider alerts, and patient education: a cluster randomized trial. Ann Intern Med. 2006; 145: 165-75.

17. Carter BL, Bergus GR, Dawson JD et al. A cluster randomized trial to evaluate physician/pharmacist collaboration to improve blood pressure control. J Clin Hypertens. 2008; 10:260-71.

18. Lai LL. Community pharmacy-based hypertension disease-management program in a Latino/Hispanic-American population. Consult Pharm. 2007; 22:4116.

19. De Souza WA, Yugar-Toledo JC, Bergsten-Mendes $G$ et al. Effect of pharmaceutical care on blood pressure control and health-related quality of life in patients with resistant hypertension. Am J Health-Syst Pharm. 2007; 64:1955-61.

20. Aguwa CN, Ukwe CV, Ekwunife OI. Effect of pharmaceutical care programme on blood pressure and quality of life in a Nigerian pharmacy. Pharm World Sci. 2008; 30:107-10.

21. Turnbull F. Effects of different bloodpressure-lowering regimens on major cardiovascular events: results of prospectively-designed overviews of randomised trials. Lancet. 2003; 362:1527-35

22. Downs SH, Black N. The feasibility of creating a checklist for the assessment of the methodological quality both of randomised and non-randomised studies of health care interventions. J Epidemiol Community Health. 1998; 52:377-84.

23. Begg CB, Mazumdar M. Operating characteristics of a rank correlation test for publication bias. Biometrics. 1994; 50 1088-101.

24. Cochran WG. The combination of estimates from different experiments. Biometrics. 1954; 10:101-29.

25. Green BB, Ralston JD, Fishman PA et al. Electronic communications and home blood pressure monitoring (e-BP) study: design, delivery, and evaluation framework. Contemp Clin Trials. 2008; 29:37695.

26. Weycker D, Edelsberg J, Vincze G et al. Blood pressure control in patients initiating antihypertensive therapy. Ann Pharmacother. 2008; 42:169-76.

27. Dean SC, Kerry SM, Cappuccio FP et al. Pilot study of potential barriers to blood pressure control in patients with inadequately controlled hypertension. Fam Pract. 2007; 24:259-62.

28. Irons BK, Lenz RJ, Anderson SL et al. A retrospective cohort analysis of the clinical effectiveness of a physician- pharmacist collaborative drug therapy management diabetes clinic. Pharmacotherapy. 2002; 22:1294-300.

29. Simpson SH, Johnson JA, Biggs RS et al. Greater effect of enhanced pharmacist care on cholesterol management in patients with diabetes mellitus: a planned subgroup analysis of the Study of Cardiovascular Risk Intervention by Pharmacists (SCRIP). Pharmacotherapy. 2004; 24:389-94.

30. Ellis SL, Carter BL, Malone DC et al. Clinical and economic impact of ambulatory care clinical pharmacists in management of dyslipidemia in older adults: the IMPROVE study. Pharmacotherapy. 2000; 20:1508-16.

31. Fischer LR, Scott LM, Boonstra DM et al. Pharmaceutical care for patients with chronic conditions. J Am Pharm Assoc. 2000; 40:174-80.

32. Bucci C, Jackevicius $\mathrm{C}, \mathrm{McF}$ arlane $\mathrm{K}$ et al. Pharmacist's contribution in a heart function clinic: patient perception and medication appropriateness. Can J Cardiol. 2003; 19:391-6.

33. Pickering TG. Home blood pressure monitoring: a new standard method for monitoring hypertension control in treated patients. Nat Clin Pract Cardiovasc Med. 2008; 5:762-3.

34. Lewis NJ, Bugdalski-Stutrud C, Abate MA et al. The medication assessment program: comprehensive medication assessments for persons taking multiple medications for chronic diseases. J Am Pharm Assoc. 2008; 48:171-80.

35. Tinelli M, Bond C, Blenkinsopp A et al. Patient evaluation of a community pharmacy medications management service. Ann Pharmacother. 2007; 41:1962-70

36. Lowey A, Moore S, Norris C et al. The cost-effectiveness of pharmacist-led treatment of cardiac risk in patients with type 2 diabetes. Pharm World Sci. 2007; 29:541-5.

37. Cote I, Moisan J, Chabot I et al. Healthrelated quality of life in hypertension: impact of a pharmacy intervention programme. J Clin Pharm Ther. 2005; 30:355-62.

38. Erhun WO, Agbani EO, Bolaji EE. Positive benefits of a pharmacist-managed hypertension clinic in Nigeria. Public Health. 2005; 119:792-8.

39. Carter BL. [Improving blood pressure control with physician/pharmacist collaboration.] Vnitr Lek. 2009; 55:389-94. In Czech.

40. Green BB, Cook AJ, Ralston JD et al. Effectiveness of home blood pressure monitoring, Web communication, and pharmacist care on hypertension control: a randomized controlled trial. JAMA. 2008; 299:2857-67.

41. McLean DL, McAlister FA, Johnson JA et al. A randomized trial of the effect of community pharmacist and nurse care on improving blood pressure management in patients with diabetes mellitus: Study of Cardiovascular Risk Intervention by Pharmacists-Hypertension
(SCRIP-HTN). Arch Intern Med. 2008; 168:2355-61.

42. Isetts BJ, Schondelmeyer SW, Artz MB et al. Clinical and economic outcomes of medication therapy management services: the Minnesota experience. J Am Pharm Assoc. 2008; 48:203-11.

43. Bunting BA, Smith BH, Sutherland SE. The Asheville Project: clinical and economic outcomes of a community-based long-term medication therapy management program for hypertension and dyslipidemia. J Am Pharm Assoc. 2008; 48:23-31.

44. Von Muenster SJ, Carter BL, Weber CA et al. Description of pharmacist interventions during physician-pharmacist co-management of hypertension. Pharm World Sci. 2008; 30:128-35.

45. Rozenfeld Y, Hunt JS. Effect of patient withdrawal on a study evaluating pharmacist management of hypertension. Pharmacotherapy. 2006; 26:1565-71.

46. McConnell KJ, Zadvorny EB, Hardy $\mathrm{AM}$ et al. Coronary artery disease and hypertension: outcomes of a pharmacistmanaged blood pressure program. Pharmacotherapy. 2006; 26:1333-41.

47. Borenstein JE, Graber G, Saltiel E et al. Physician-pharmacist comanagement of hypertension: a randomized, comparative trial. Pharmacotherapy. 2003; 23:209-16.

48. Garcao JA, Cabrita J. Evaluation of a pharmaceutical care program for hypertensive patients in rural Portugal. J Am Pharm Assoc. 2002; 42:858-64.

49. Godley P, Nguyen A, Yokoyama $\mathrm{K}$ et al. Improving hypertension care in a large group-model MCO. Am J Health-Syst Pharm. 2003; 60:554-64.

50. Okamoto MP, Nakahiro RK. Pharmacoeconomic evaluation of a pharmacistmanaged hypertension clinic. Pharmacotherapy. 2001; 21:1337-44

51. Reid F, Murray P, Storrie M. Implementation of a pharmacist-led clinic for hypertensive patients in primary care-a pilot study. Pharm World Sci. 2005; 27:202-7.

52. Hennessy S, Leonard CE, Yang $\mathrm{W}$ et al. Effectiveness of a two-part educational intervention to improve hypertension control: a cluster-randomized trial. Pharmacotherapy. 2006; 26:1342-7.

53. Murray MD, Harris LE, Overhage JM et al. Failure of computerized treatment suggestions to improve health outcomes of outpatients with uncomplicated hypertension: results of a randomized controlled trial. Pharmacotherapy. 2004; 24:324-37.

54. Santschi V, Rodondi N, Bugnon O et al. Impact of electronic monitoring of drug adherence on blood pressure control in primary care: a cluster 12-month randomised controlled study. Eur J Intern Med. 2008; 19:427-34.

55. Machado M, Bajcar J, Guzzo GC et al. Sensitivity of patient outcomes to pharmacist interventions. Part I: systematic review and meta-analysis in diabetes management. Ann Pharmacother. 2007; $41: 1569-82$ 
56. Blenkinsopp A. Extended adherence support by community pharmacists for patients with hypertension: a randomised controlled trial. Int J Pharm Pract. 2000; 8:165-75.

57. Brouker ME, Gallagher K, Larrat EP et al Patient compliance and blood pressure control on a nuclear-powered aircraft carrier: impact of a pharmacy officer. Mil Med. 2000; 165:106-10.

58. Chabot I, Moisan J, Gregoire JP et al. Pharmacist intervention program for control of hypertension. Ann Pharmacother. 2003; 37:1186-93.

59. De Castro MS, Fuchs FD, Santos MC et al. Pharmaceutical care program for patients with uncontrolled hypertension. Report of a double-blind clinical trial with ambulatory blood pressure monitoring. Am J Hypertens. 2006; 19:528-33.

60. Mehos BM, Saseen JJ, MacLaughlin EJ. Effect of pharmacist intervention and initiation of home blood pressure monitoring in patients with uncontrolled hypertension. Pharmacotherapy. 2000; 20:1384-9.

61. Sookaneknun P, Richards RM, Sanguansermsri J et al. Pharmacist involvement in primary care improves hypertensive patient clinical outcomes. Ann Pharmacother. 2004; 38:2023-8.

62. Vivian EM. Improving blood pressure control in a pharmacist-managed hypertension clinic. Pharmacotherapy. 2002; 22:1533-40.

63. Zillich AJ, Sutherland JM, Kumbera PA et al. Hypertension outcomes through blood pressure monitoring and evaluation by pharmacists (HOME study). $J$ Gen Intern Med. 2005; 20:1091-6.

64. Duval S, Tweedie R. Trim and fill: a simple funnel-plot-based method of testing and adjusting for publication bias in meta-analysis. Biometrics. 2000; 56:45563.

65. Milchak JL, Carter BL, James PA et al. Measuring adherence to practice guidelines for the management of hypertension: an evaluation of the literature. Hypertension. 2004; 44:602-8.

66. Carter BL, Ardery G, Dawson JD et al. Physician and pharmacist collaboration to improve blood pressure control. Arch Intern Med. 2009; 169:1996-2002.

67. Carter BL, Rogers M, Daly J et al. The potency of team-based care interventions for hypertension: a meta-analysis. Arch Intern Med. 2009; 169:1748-55.

68. Christensen DB, Williams B, Goldberg $\mathrm{HI}$ et al. Assessing compliance to antihypertensive medications using computerbased pharmacy records. Med Care. 1997; 35:1164-70.

69. McDonald HP, Garg AX, Haynes RB. Interventions to enhance patient adherence to medication prescriptions: scientific review. JAMA. 2002; 288:2868-79.

70. Morisky DE, Green LW, Levine DM. Concurrent and predictive validity of a self-reported measure of medication adherence. Med Care. 1986; 24:67-74. 
Copyright of American Journal of Health-System Pharmacy is the property of American Society of Health System Pharmacists and its content may not be copied or emailed to multiple sites or posted to a listserv without the copyright holder's express written permission. However, users may print, download, or email articles for individual use. 